\title{
The influence of the Cyclin D I 870 G>A polymorphism as an endometrial cancer risk factor
}

\author{
Katie A Ashton ${ }^{1}$, Anthony Proietto ${ }^{2,3}$, Geoffrey Otton ${ }^{2,3}$, Ian Symonds ${ }^{3}$, \\ Mark McEvoy ${ }^{3}$, John Attia ${ }^{3}$, Michael Gilbert ${ }^{4}$, Ute Hamann ${ }^{4}$ and \\ Rodney J Scott*1,5
}

\begin{abstract}
Address: ${ }^{1}$ Discipline of Medical Genetics, School of Biomedical Sciences, Faculty of Health, University of Newcastle, Australia and the Hunter Medical Research Institute, NSW, 2308, Australia, ${ }^{2}$ Hunter Centre for Gynaecological Cancer, John Hunter Hospital, Newcastle, NSW, 2305, Australia, ${ }^{3}$ School of Medicine and Public Health, Faculty of Health, University of Newcastle, NSW, 2305, Australia, ${ }^{4}$ Molecular Genetics of Breast Cancer, German Cancer Research Center, 69120 Heidelberg, Germany and ${ }^{5}$ Division of Genetics, Hunter Area Pathology Service, John Hunter Hospital, Newcastle, NSW, 2305, Australia

Email: Katie A Ashton - katie.ashton@studentmail.newcastle.edu.au; Anthony Proietto - aproietto@bigpond.com; Geoffrey Otton - gotton@bigpond.net; Ian Symonds - ian.symonds@newcastle.edu.au; Mark McEvoy - mark.mcevoy@newcastle.edu.au; John Attia - john.attia@newcastle.edu.au; Michael Gilbert - m.gilbert@dkfz-heidelberg.de; Ute Hamann - u.hamann@dkfz-heidelberg.de; Rodney J Scott* - rodney.scott@newcastle.edu.au

* Corresponding author
\end{abstract}

Published: 29 September 2008

BMC Cancer 2008, 8:272 doi:10.1 /86/147|-2407-8-272
Received: 20 May 2008

Accepted: 29 September 2008

This article is available from: http://www.biomedcentral.com//47/-2407/8/272

(C) 2008 Ashton et al; licensee BioMed Central Ltd.

This is an Open Access article distributed under the terms of the Creative Commons Attribution License (http://creativecommons.org/licenses/by/2.0), which permits unrestricted use, distribution, and reproduction in any medium, provided the original work is properly cited.

\begin{abstract}
Background: Cyclin DI is integral for the GI to $S$ phase of the cell cycle as it regulates cellular proliferation. A polymorphism in cyclin DI, $870 \mathrm{G}>\mathrm{A}$, causes overexpression and supports uncontrollable cellular growth. This polymorphism has been associated with an increased risk of developing many cancers, including endometrial cancer.
\end{abstract}

Methods: The $870 \mathrm{G}>\mathrm{A}$ polymorphisms ( $r$ 605965) in the cyclin DI gene was genotyped in an Australian endometrial cancer case-control population including $|9|$ cases and 29| controls using real-time PCR analysis. Genotype analysis was performed using chi-squared $\left(\chi^{2}\right)$ statistics and odds ratios were calculated using unconditional logistic regression, adjusting for potential endometrial cancer risk factors.

Results: Women homozygous for the variant cyclin DI 870 AA genotype showed a trend for an increased risk of developing endometrial cancer compared to those with the wild-type GG genotype, however this result was not statistically significant (OR I.692 95\% Cl (0.939-3.049), $\mathrm{p}=$ 0.080 ). Moreover, the $870 \mathrm{G}>\mathrm{A}$ polymorphism was significantly associated with family history of colorectal cancer. Endometrial cancer patients with the homozygous variant AA genotype had a higher frequency of family members with colorectal cancer in comparison to endometrial cancer patients with the GG and combination of GG and GA genotypes (GG versus AA; OR 2.95I, 95\% $\mathrm{Cl}(\mathrm{I} .026-8.49 \mathrm{I}), \mathrm{p}=0.045$, and $\mathrm{GG}+\mathrm{GA}$ versus $\mathrm{AA} ; \mathrm{OR} 2.265,95 \% \mathrm{Cl}(\mathrm{I} .048-4.894), \mathrm{p}=0.038$, respectively).

Conclusion: These results suggest that the cyclin DI $870 \mathrm{G}>\mathrm{A}$ polymorphism is possibly involved in the development of endometrial cancer. A more complex relationship was observed between this polymorphism and familial colorectal cancer. 


\section{Background}

Cyclin D1 (CCND1) is a key protein in the regulation of the cell cycle at the G1 to S phase transition, and is essential for regulation of proliferation, differentiation and transcriptional control [1]. Overexpression of cyclin D1 induces excessive cellular proliferation and is a feature of a number of cancers, including endometrial and colorectal cancer [2-6]. Specifically for endometrial cancer, numerous studies have reported increased cellular proliferation co-existing with progressive derailment of cyclin $\mathrm{D} 1$, leading to the progression of hyperplasia to endometrial endometriod carcinoma [7-9]. Many association studies have focused their attention to the functionally significant $870 \mathrm{G}>\mathrm{A}$ polymorphism in cyclin D1 which creates two different splice variant transcripts [10]. The normal transcript encodes exon 5 which is essential for ubiquitin-mediated proteolysis whereas the other transcript lacks the destruction box in exon 5 and increases the half life of cyclin D1 [10]. The A allele of the $870 \mathrm{G}>\mathrm{A}$ polymorphism in cyclin D1 encodes the alternate transcript and increased levels of cyclin D1 are also evident in the heterozygous state $[10,11]$.

Previous studies have reported inconsistent findings for the cyclin D1 polymorphism and a number of different cancers. With respect to endometrial cancer, there has been one published report on the association between the cyclin D1 $870 \mathrm{G}>\mathrm{A}$ polymorphism and endometrial cancer risk in Korean women [12]. Kang et al. (2005) [12] reported that endometrial cancer patients with the $\mathrm{AA}$ genotype had an increased risk of disease compared to carriers of the GG genotype and the combination of the GG and GA genotypes, suggestive of a recessive model for the A allele.

Endometrial cancer is the most common gynaecological malignancy in Western countries and it is important to determine the genetic variants associated with disease since the genetic basis is poorly understood. Estrogen and its metabolites have been associated with an increased risk of developing endometrial cancer due to their ability to cause DNA damaging events [13], therefore cell cycle control is integral for the recognition, repair and/or elimination of DNA damage to prevent the initiation of cancer.

The focus of this study was to examine the $870 \mathrm{G}>\mathrm{A}$ polymorphism in cyclin D1 and its association with endometrial cancer risk in Caucasians including 191 endometrial cancer cases and 291 controls.

\section{Methods \\ Study Population}

This study initially consisted of 213 consecutively recruited women with histologically confirmed endometrial cancer who presented for treatment at the Hunter
Centre for Gynaecological Cancer, John Hunter Hospital, Newcastle, New South Wales, Australia between the years 1992 and 2005. Women that had additionally been diagnosed with breast cancer were excluded from this study.

The final analysis included 191 endometrial cancer patients. Data on reproductive and environmental risk factors including ethnicity, body mass index (BMI), diabetes, high blood pressure (HBP), age of diagnosis of endometrial cancer, age of menarche, age of menopause, other personal cancer history, family history of cancer (defined as cancer in the index patient plus one or more first or second degree relatives diagnosed with cancer), parity, breastfeeding, oral contraceptive use, chemotherapy, radiotherapy, hormone therapy (HT), smoking and alcohol use was collected using self reported questionnaires. Information regarding recurrence, stage, grade and histology of endometrial cancer was collected from the medical records.

The control population consisted of 291 women who were recruited between the years 2004 and 2005 for the Hunter Community Study. This study aims to identify genetic and environmental factors associated with ageing in a cohort of individuals obtained from the Hunter region, Newcastle, New South Wales, Australia. Any control that had a prior diagnosis of either breast or endometrial cancer was excluded from the study. Controls were matched to cases by sex and age.

All participants provided informed written consent prior to participation in this study. Ethics approval was obtained from the Human Research Ethics Committee, University of Newcastle and the Hunter Area Research Ethics Committee, Hunter New England Health Service, Newcastle, New South Wales, Australia.

\section{DNA Isolation}

Genomic DNA was extracted from $10 \mathrm{ml}$ EDTA blood as previously described [14].

\section{Molecular Analysis}

Genotyping of the cyclin D1 870 G>A polymorphism (rs603965) was performed on an ABI PRISM ${ }^{\circledR} 7500$ RealTime PCR System (PE Applied Biosystems, Foster City, $\mathrm{CA})$, using primers and probes from Assay-by-Demand (Applied Biosystems) (assay ID: C_744725_1). The assay was performed under universal conditions previously described [15]. The genotyping results were confirmed by a second laboratory research assistant and 5\% of the samples were re-genotyped with $100 \%$ concordance. Any sample where a genotype could not be accurately assessed was re-genotyped. If it failed a second time, it was discarded from the analysis. The overall call rates were in the range from $99.7-100 \%$. 


\section{Statistical Analysis}

Power calculations were performed using Quanto (Version 1.2.3, May 2007, http://hydra.usc.edu/GxE. The number of cases and controls were chosen to detect a 2 fold increased risk, assuming a dominant genetic model, minor allele frequency of $6.5 \%, \mathrm{p}=0.05,80 \%$ power and 1.52 control/case ratio. For each polymorphism, HardyWeinberg Equilibrium (HWE) was calculated in the control groups to check for compliance using the Institute for Human Genetics, statistics website, http://ihg2.helm holtz-muenchen.de/ihg/snps.html (Munich, Germany). To determine differences in genotype frequencies and environmental and reproductive risk factors between the cases and controls, chi-squared $\left(\chi^{2}\right)$ statistics, odds ratios (ORs) and 95\% confidence intervals (CI) were calculated using unconditional logistic regression. Multivariate unconditional logistic regression was performed to determine if any risk factors altered the significance of the genotype frequency results. The risk factors taken into account were: BMI ( $<25$ and $\geq 25 \mathrm{~kg} / \mathrm{m}^{2}$ ) diabetes (yes/ no), HBP (yes/no), HT (yes/no), personal history of cancer (yes/no), smoking (ever/never) and alcohol consumption (ever/never). Other risk factors such as age of menopause were not included in the analysis since this information was not available for the controls.

The genotype frequencies of the cyclin D1 870 G>A polymorphism was compared in the case group stratified for the following environmental and reproductive risk factors; BMI ( $<25$ versus $>=25)$, age of menarche $(<12 \mathrm{v}\rangle=$ 12 ), age of menopause ( $<50$ versus $>=50$ ), parity (yes/ no), oral contraceptive use (ever/never), HBP (yes/no), diabetes (yes/no), personal history of ovarian, colorectal, and/or cervical cancer (yes/no), radiotherapy (yes/no), chemotherapy (yes/no), hormone therapy (yes/no), family history of uterine, breast, colorectal and/or ovarian cancer (yes/no, defined as one first or second degree relative with cancer), smoking (ever/never), alcohol (ever/ never), stage of cancer, grade of cancer, histology and cancer recurrence. This analysis was performed by using chisquared $\left(\chi^{2}\right)$ analysis and ORs and 95\% CIs were calculated using unconditional logistic regression.

T-tests were used to determine differences in the age of diagnosis of endometrial cancer by genotype. Kaplan Meier survival analysis was used to plot the cumulative survival versus the patient's age of diagnosis of endometrial cancer. By comparing the Kaplan-Meier survival curves for each genotype, we tested if there were differences in the age of diagnosis of endometrial cancer by genotype. The Wilcoxon's test was used to determine the significance of observations from early ages of diagnosis, log-rank test, which gives more weight to later ages and Tarone-Ware test, which is an intermediate of the two other tests were used to examine the homogeneity of the survival curves. The polymorphisms that showed a statistically significant difference between the genotypes and the age of diagnosis of endometrial cancer for all three statistical tests were further examined by a multivariate Cox regression model where a number of specific risk factors were incorporated into the analysis.

The significance levels of all tests were set at $\mathrm{p}<0.05$ and were two-sided. All statistical analysis was performed with Intercooled STATA 8.2 (Stata Corp., College Station, TX, USA), SPSS Version 15 (SPSS Inc. Chicago, IL, USA) and GraphPad Instat version 3.06 (GraphPad Software, San Diego, CA, USA).

\section{Results}

Cases and controls were different with respect to potential endometrial cancer risk factors, including HBP, diabetes, HT, alcohol consumption, personal history of any cancer, personal history of ovarian cancer, cervical cancer and other cancers. The characteristics of the cases and controls are shown in table 1 . The distributions of the cyclin D1 genotypes among the controls did not deviate from HWE.

The genotype frequencies were compared between the cases and controls for the cyclin D1 $870 \mathrm{G}>\mathrm{A}$ polymorphism, however no significant differences were observed (table 2). However, there was a trend for increased risk of developing endometrial cancer for women with the AA genotype compared to those with the GG genotype $\left(\mathrm{OR}_{\mathrm{adj}}\right.$ 1.692 95\% CI (0.939-3.049), $\mathrm{p}=0.080)$.

Kaplan-Meier survival analysis and T-tests were used to evaluate the influence of the cyclin D1 $870 \mathrm{G}>\mathrm{A}$ polymorphism on the age of diagnosis of endometrial cancer. No significant differences were observed (data not shown).

Family histories of other cancers in association with the index endometrial cancer cases were identified in subsets of patients. The disease associations included first and/or second degree relatives with breast, ovarian, endometrial and colorectal cancer. No relationships between the presence of the $870 \mathrm{G}>\mathrm{A}$ SNP and endometrial cancer in association with family clusterings of breast, ovarian or endometrial cancer were observed. There was, however, a significant association between the cyclin D1 $870 \mathrm{G}>\mathrm{A}$ polymorphism and family history of colorectal cancer shown in table 3. Endometrial cancer patients with the variant (AA) genotype had a higher frequency of family members with colorectal cancer compared to those with the GG and GA genotypes (GG versus AA; OR 2.951, 95\% CI (1.026-8.491), $\mathrm{p}=0.045$, and GG+GA versus AA; OR $2.265,95 \%$ CI $(1.048-4.894), \mathrm{p}=0.038)$.

In regards to the other environmental and reproductive risk factors examined in the case group, the genotype fre- 
Table I: Comparison of Environmental and Reproductive Risk Factors between Cases and Controls

\begin{tabular}{|c|c|c|c|c|c|c|}
\hline Risk Factor & Group & Cases n (\%) & Controls n (\%) & OR & $95 \% \mathrm{Cl}$ & $P$ value \\
\hline \multirow[t]{2}{*}{ High Blood Pressure (yes/no) } & yes & $107(56.0)$ & $114(39.2)$ & 1.978 & $1.366-2.864$ & $\mathrm{p}<0.001$ \\
\hline & no & $84(44.0)$ & $177(60.8)$ & & & \\
\hline \multirow[t]{2}{*}{ Diabetes (yes/no) } & yes & $44(23.0)$ & $31(10.7)$ & 2.51 & $1.519-4.148$ & $\mathrm{P}<0.001$ \\
\hline & no & 147 (77.0) & $260(89.3)$ & & & \\
\hline \multirow[t]{2}{*}{ Hormone Therapy (yes/no) } & yes & $47(24.6)$ & $40(13.7)$ & 2.048 & $1.282-3.273$ & $p=0.003$ \\
\hline & no & $144(75.4)$ & $25 I(86.3)$ & & & \\
\hline \multirow[t]{2}{*}{ Alcohol consumption (ever/never) } & ever & $92(48.2)$ & $228(78.4)$ & 0.257 & $0.172-0.382$ & $\mathrm{p}<0.001$ \\
\hline & never & $99(51.8)$ & $63(21.6)$ & & & \\
\hline \multirow[t]{2}{*}{ BMI } & $<25 \mathrm{~kg} / \mathrm{m}^{2}$ & $34(19.1)$ & $72(24.7)$ & 0.718 & $0.454-1.136$ & $p=0.157$ \\
\hline & $>=25 \mathrm{~kg} / \mathrm{m}^{2}$ & 144 (80.9) & $219(75.3)$ & & & \\
\hline \multirow[t]{2}{*}{ Smoking (ever/never) } & ever & $52(27.2)$ & $68(23.4)$ & 1.227 & $0.807-1.865$ & $P=0.338$ \\
\hline & never & $139(72.8)$ & $223(76.6)$ & & & \\
\hline \multirow[t]{2}{*}{ Ovarian Cancer (yes/no) } & yes & $7(3.7)$ & I (0.3) & 11.033 & $1.346-90.403$ & $p=0.025$ \\
\hline & no & $184(96.3)$ & $290(99.7)$ & & & \\
\hline \multirow[t]{2}{*}{ Cervical Cancer (yes/no) } & yes & $8(4.2)$ & $2(0.7)$ & 6.317 & $1.327-30.077$ & $p=0.021$ \\
\hline & no & $183(95.8)$ & $289(99.3)$ & & & \\
\hline \multirow[t]{2}{*}{ History of Ovarian or Cervical Cancer (yes/no) } & yes & $15(7.9)$ & $3(1.0)$ & 8.182 & $2.335-28.663$ & $p=0.001$ \\
\hline & no & $176(92.1)$ & $288(99.0)$ & & & \\
\hline \multirow[t]{2}{*}{ Personal History of Any Cancer (yes/no) } & yes & $5 I(26.7)$ & $28(9.6)$ & 3.422 & $2.066-5.667$ & $\mathrm{P}<0.001$ \\
\hline & no & $140(73.3)$ & $263(90.4)$ & & & \\
\hline \multirow[t]{2}{*}{ History of Skin Cancer (yes/no) } & yes & $20(10.5)$ & $19(6.5)$ & 1.674 & $0.869-3.228$ & $p=0.124$ \\
\hline & no & $|7|(89.5)$ & $272(93.5)$ & & & \\
\hline \multirow[t]{2}{*}{ History of Bowel Cancer (yes/no) } & yes & $10(5.2)$ & $8(2.7)$ & 1.954 & $0.757-5.045$ & $p=0.166$ \\
\hline & no & $|8|(94.8)$ & $283(97.3)$ & & & \\
\hline
\end{tabular}

Note: BMI not known for 13 cases.

quencies of the cyclin D1 $870 \mathrm{G}>\mathrm{A}$ polymorphism showed no further significant results.

\section{Discussion}

It is well known that endogenous and exogenous estrogen is implicated in endometrial cancer etiology since their products and metabolites have the ability to cause DNA damage. Given the importance of cell cycle control for the maintenance of genomic integrity, it is conceivable that polymorphisms in the genes that drive these processes alter the efficiency of DNA repair, leading to disease initi- ation. The current study took into account a series of environmental and reproductive risk factors for both the cases and controls and the results support previous epidemiological data for the listed risk factors indicating that there were no unusual environmental characteristics associated with the study population.

This study focused on the $870 \mathrm{G}>\mathrm{A}$ polymorphism in cyclin $\mathrm{D} 1$ and its association with endometrial cancer risk. The $870 \mathrm{G}>\mathrm{A}$ polymorphism was not significantly associated with endometrial cancer risk. However, a trend

Table 2: Association of Cyclin DI 870 G>A (rs603965) Polymorphism with Endometrial Cancer Risk

\begin{tabular}{|c|c|c|c|c|c|}
\hline Genotype & Cases n (\%) & Controls n (\%) & $\chi^{2}$ & OR $(95 \% \mathrm{Cl})$ and $p$ value & \\
\hline \multirow[t]{3}{*}{ GG } & $49(25.7)$ & $93(32.1)$ & $p=0.161$ & 1.00 (reference) & \\
\hline & & & & $1.262(0.77 \mathrm{I}-2.066)_{\mathrm{adj} \#}$ & $p=0.355$ \\
\hline & & & & $1.256(0.815-1.938)$ & $p=0.302$ \\
\hline \multirow[t]{2}{*}{ AA } & $48(25.1)$ & $55(19.0)$ & & $1.692(0.939-3.049)_{\mathrm{adj} \#}$ & $P=0.080$ \\
\hline & & & & $1.656(0.989-2.784)$ & $p=0.057$ \\
\hline \multirow[t]{2}{*}{$\mathrm{GA}+\mathrm{AA}$} & $142(74.3)$ & $197(67.9)$ & $p=0.131 t$ & $\mathrm{I} .383(0.869-2.20 \mathrm{I})_{\mathrm{adj} \#}$ & $P=0.172$ \\
\hline & & & & $1.368(0.910-2.057)$ & $p=0.132$ \\
\hline \multirow[t]{2}{*}{$\mathrm{GG}+\mathrm{GA}$} & I 43 (74.9) & $235(81.0)$ & $p=0.107 \ddagger$ & $1.458(0.889-2.393)_{\mathrm{adj} \#}$ & $p=0.135$ \\
\hline & & & & $1.434(0.924-2.226)$ & $p=0.108$ \\
\hline
\end{tabular}

Note: Minor Allele Frequency (MAF) 0.317.

\# OR $\mathrm{R}_{\text {adj: }}$ : Adjusted for BMI, HBP, diabetes, $\mathrm{HT}$, personal history of cancer, smoking and alcohol use.

t $P$ value: Wild type genotype (GG) compared to combination of heterozygous and homozygous variant genotypes (GA+AA).

$\ddagger P$ value: Homozygous variant genotype (AA) compared to combination of wild type and heterozygous genotypes (GG+GA). 
Table 3: Association of Cyclin DI 870 G>A (rs603965) Polymorphism and Family History of Colorectal Cancer in Endometrial Cancer Cases

\begin{tabular}{|c|c|c|c|c|c|}
\hline \multirow[t]{2}{*}{ Genotype } & \multicolumn{2}{|c|}{ FH of Colorectal Cancer in Endometrial Cancer Cases $(n=191)$} & \multirow[t]{2}{*}{$\chi^{2}$} & \multicolumn{2}{|c|}{ OR $(95 \% \mathrm{Cl})$ and $p$ value } \\
\hline & Yes n (\%) & No n (\%) & & & \\
\hline GG & $6(3.1)$ & $43(22.5)$ & $p=0.084$ & 1.00 (reference) & \\
\hline GA & $16(8.4)$ & $78(40.8)$ & & $1.470(0.536-4.034)$ & $p=0.454$ \\
\hline AA & $14(7.3)$ & $34(17.8)$ & & $2.95 I(I .026-8.49 I)$ & $p=0.045$ \\
\hline $\mathrm{GA}+\mathrm{AA}$ & $30(15.7)$ & $112(58.6)$ & $p=0.170 \#$ & $1.920(0.747-4.936)$ & $p=0.176$ \\
\hline$G G+G A$ & $22(11.5)$ & $121(63.4)$ & $p=0.035 \dagger$ & $2.265(1.048-4.894)$ & $p=0.038$ \\
\hline
\end{tabular}

Note: $\mathrm{FH}$, family history.

\# $p$ value: Wild type genotype (GG) compared to combination of heterozygous and homozygous variant genotypes (GA+AA).

t $p$ value: Homozygous variant genotype (AA) compared to combination of wild type and heterozygous genotypes (GG+GA).

towards the AA genotype imparting an increased risk of endometrial cancer compared to the GG genotype was observed. These results support the study of Kang et al. (2005) [12] who found a significant association between the AA genotype and an increased risk in endometrial cancer development in Korean women (GG+GA versus AA, $\left.\mathrm{OR}_{\mathrm{adj}} 2.63(1.04-6.66), \mathrm{p}=0.041\right)$ and suggests that this polymorphism is acting as a disease modifier. Even though we did not observe a statistically significant result, the underlying biological plausibility remains consistent between the two studies. The most likely explanation for the difference in the significance of the results between the current study and that of Kang et al. (2005) [12] is the influence of different environmental factors affecting disease risk. A number of studies have shown that overexpression of cyclin D1 is associated with endometrial cancer and that it is an early event in tumourigenesis $[3,4,6-9]$. One report showed that $50 \%(7 / 14)$ of endometrial carcinomas had cyclin D1 overexpression and that there was no immunopositive difference between these carcinomas and simple hyperplasia which is a precursor for endometrial cancer development [3].

From the study participants two main familial associations were observed, one with colorectal cancer (36 endometrial cancer patients $(18.8 \%)$ with family history of colorectal cancer) and the other with breast cancer (44 endometrial cancer patients $(23.0 \%)$ with family history of breast cancer). Interestingly, analysing family history of colorectal cancer in patients with endometrial cancer and the cyclin D1 $870 \mathrm{G}>\mathrm{A}$ polymorphism showed that endometrial cancer patients with the AA genotype had a higher frequency of family members with colorectal cancer compared to endometrial cancer patients with the GG or GA genotype combinations.

The association between endometrial cancer and colorectal cancer is well recognised in Lynch Syndrome (or HNPCC); however, endometrial cancer associations with other malignancies are less well defined and there is little written in the literature about breast/endometrial cancer familial clustering. No association was observed between the cyclin D1 G870A SNP and endometrial/breast cancer families whereas an association was observed between this polymorphism and the increased likelihood of colorectal cancer in other family members.

There have been a number of studies that have focused on the cyclin D1 $870 \mathrm{G}>$ A polymorphism and colorectal cancer development however these reports are somewhat conflicting [16-18]. Some studies have reported an association between the cyclin D1 $870 \mathrm{G}>\mathrm{A}$ polymorphism and the age of diagnosis of colorectal disease in HNPCC [1921]. Endometrial cancer is the most common cancer in women with HNPCC and the second most common cancer overall in this syndrome [22], therefore the association of the cyclin D1 $870 \mathrm{G}>\mathrm{A}$ polymorphism and a family history of colorectal cancer is intriguing and suggests that this polymorphism may be related to the increased risk of endometrial cancer in HNPCC.

This study has a number of strengths since it was a population-based case-control investigation that had a relatively large sample size to detect an association and detailed information of specific risk factors. However, these results must be confirmed in a larger population and more studies should be conducted on the association between the cyclin D1 $870 \mathrm{G}>\mathrm{A}$ polymorphism and endometrial cancer risk. Additionally, the relationship between the cyclin D1 $870 \mathrm{G}>\mathrm{A}$ polymorphism and HNPCC, specifically hMSH2 mutation carriers, should also be confirmed in further studies.

In conclusion, we have shown that the $870 \mathrm{G}>\mathrm{A}$ polymorphism in cyclin D1 may be associated with endometrial cancer risk and provided support for an association with colorectal cancer risk.

\section{Acknowledgements}

The authors would like to acknowledge the NBN Children's Cancer Research Group, the University of Newcastle, the Centre for Information 
Based Medicine, Ms Jennie Thomas and HMRI program funds used for this project. The study sponsors had no role in the study design, in the collection, analysis and interpretation of data; in the writing of the manuscript; and in the decision to submit the manuscript for publication.

\section{References}

I. Sherr C): Cancer cell cycles. Science (New York, NY) 1996, 274(5293): 1672-1677.

2. Arber N, Hibshoosh H, Moss SF, Sutter T, Zhang Y, Begg M, Wang S, Weinstein IB, Holt PR: Increased expression of cyclin DI is an early event in multistage colorectal carcinogenesis. Gastroenterology 1996, II 0(3):669-674.

3. Choudhury M, Bansal S: Expression of cyclin DI in endometrial hyperplasia and endometrial carcinoma. Indian journal of pathology \& microbiology 2007, 50(4):708-7I0.

4. Watanabe J, Kamata Y, Seo N, Okayasu I, Kuramoto H: Stimulatory effect of estrogen on the growth of endometrial cancer cells is regulated by cell-cycle regulators. The Journal of steroid biochemistry and molecular biology 2007, 107(3-5): 163-171.

5. Horree N, van Diest PJ, Sie-Go DM, Heintz AP: The invasive front in endometrial carcinoma: higher proliferation and associated derailment of cell cycle regulators. Human pathology 2007, 38(8): $1232-1238$

6. Ruhul Quddus M, Latkovich P, Castellani WJ, James Sung C, Steinhoff MM, Briggs RC, Miranda RN: Expression of cyclin DI in normal, metaplastic, hyperplastic endometrium and endometrioid carcinoma suggests a role in endometrial carcinogenesis. Archives of pathology \& laboratory medicine 2002, I 26(4):459-463.

7. Horree N, van Diest PJ, Groep P van der, Sie-Go DM, Heintz AP: Progressive derailment of cell cycle regulators in endometrial carcinogenesis. Journal of clinical pathology 2008, 6 I (I):36-42.

8. Semczuk A, Jakowicki JA: Alterations of pRb I-cyclin D I-cdk4/6p I6(INK4A) pathway in endometrial carcinogenesis. Cancer letters 2004, 203(I): I- 12.

9. Smid-Koopman E, Blok LJ, Chadha-Ajwani S, Helmerhorst TJ, Brinkmann AO, Huikeshoven Fj: Gene expression profiles of human endometrial cancer samples using a cDNA-expression array technique: assessment of an analysis method. British journal of cancer 2000, 83(2):246-25I.

10. Betticher DC, Thatcher N, Altermatt HJ, Hoban P, Ryder WD, Heighway J: Alternate splicing produces a novel cyclin DI transcript. Oncogene 1995, II(5): I005-10II.

II. Hosokawa Y, Arnold A: Mechanism of cyclin DI (CCNDI, PRADI) overexpression in human cancer cells: analysis of allele-specific expression. Genes, chromosomes \& cancer 1998, 22(I):66-7I.

12. Kang S, Kim JW, Park NH, Song YS, Kang SB, Lee HP: Cyclin DI polymorphism and the risk of endometrial cancer. Gynecologic oncology 2005, 97(2):431-435.

13. Yager JD, Liehr JG: Molecular mechanisms of estrogen carcinogenesis. Annual review of pharmacology and toxicology 1996, 36:203-232.

14. Miller SA, Dykes DD, Polesky HF: A simple salting out procedure for extracting DNA from human nucleated cells. Nucleic acids research 1988, 16(3): 1215.

15. Talseth BA, Meldrum C, Suchy J, Kurzawski G, Lubinski J, Scott RJ: Age of diagnosis of colorectal cancer in HNPCC patients is more complex than that predicted by $R 72 P$ polymorphism in TP53. International journal of cancer 2006, I I 8(I 0):2479-2484.

16. Kong S, Wei Q, Amos Cl, Lynch PM, Levin B, Zong J, Frazier ML: Cyclin DI polymorphism and increased risk of colorectal cancer at young age. Journal of the National Cancer Institute 200I, 93(14): I 106-I I08.

17. McKay JA, Douglas JJ, Ross VG, Curran S, Murray GI, Cassidy J, McLeod HL: Cyclin DI protein expression and gene polymorphism in colorectal cancer. Aberdeen Colorectal Initiative. International journal of cancer 2000, 88(I):77-8I.

18. Porter TR, Richards FM, Houlston RS, Evans DG, Jankowski JA, Macdonald F, Norbury G, Payne SJ, Fisher SA, Tomlinson I, et al.: Contribution of cyclin dl (CCNDI) and E-cadherin (CDHI) polymorphisms to familial and sporadic colorectal cancer. Oncogene 2002, 2 I(I 2): I 928-1933.

19. Bala S, Peltomaki P: CYCLIN DI as a genetic modifier in hereditary nonpolyposis colorectal cancer. Cancer research 200I, 6I(16):6042-6045.
20. Kong S, Amos Cl, Luthra R, Lynch PM, Levin B, Frazier ML: Effects of cyclin DI polymorphism on age of onset of hereditary nonpolyposis colorectal cancer. Cancer research 2000, 60(2):249-252.

21. Talseth BA, Ashton KA, Meldrum C, Suchy J, Kurzawski G, Lubinski J, Scott RJ: Aurora-A and Cyclin DI polymorphisms and the age of onset of colorectal cancer in hereditary nonpolyposis colorectal cancer. International journal of cancer 2008, I 22(6): : 273- I 277.

22. Hampel H, Stephens JA, Pukkala E, Sankila R, Aaltonen LA, Mecklin JP, de la Chapelle A: Cancer risk in hereditary nonpolyposis colorectal cancer syndrome: later age of onset. Gastroenterology 2005, I29(2):415-42I.

\section{Pre-publication history}

The pre-publication history for this paper can be accessed here:

\section{http://www.biomedcentral.com/1471-2407/8/272/pre} pub
Publish with Bio Med Central and every scientist can read your work free of charge

"BioMed Central will be the most significant development for disseminating the results of biomedical research in our lifetime. "

Sir Paul Nurse, Cancer Research UK

Your research papers will be:

- available free of charge to the entire biomedical community

- peer reviewed and published immediately upon acceptance

- cited in PubMed and archived on PubMed Central

- yours - you keep the copyright
BioMedcentral 